\title{
EDITORIAL Post-craniotomy pain: A neglected entity
}

Treatment of pain following craniotomy is an important but neglected subject in most centres practicing neurosurgery. Pain intensity following craniotomy is assumed to be tolerable, not deserving serious attention compared with severe pain produced by other surgical procedures. Suggested reasons for this wrong assumption include lesser number of pain receptors in dura, pain insensitivity of the brain, reduced pain fibre density along the incision lines or development of autoanalgesia. ${ }^{[1]}$ A combination of the absence of quality studies to address this aspect as also a lack of consensus on pain management in these patients adds to the apathy of healthcare providers towards these patients. Compounding the issue is the common teaching in the past has been that it is unsafe to administer stronger opioids following intracranial surgery due to their adverse effects on sensorium, respiration and pupils, and thus clouding the neurological examination. However, what we tend to overlook is that following craniotomy neurosurgical patients may be unable to convey effectively to the healthcare providers of their pain intensity and need for good analgesia. Moreover, associated symptoms and impact on patient's performance from post-craniotomy pain remain poorly understood. ${ }^{[2]}$ However, there is a genuine fear that unsatisfactory pain control may negatively impact recovery and outcomes of these patients, and in the long run, they may become victims of chronic pain. Pain influences each and every organ system of the body. It is a common observation that suboptimal or undertreated pain results in hypertension and tachycardia. Increased blood pressure in the face of deranged cerebral autoregulation (which is most likely a case following intracranial surgery) may impair cerebral blood flow with attendant serious complications, contributing to increased morbidity and mortality. ${ }^{[3]}$

It was not until 1996 when De Benedittis et al. undertook a pilot study to assess post-operative pain in neurosurgical population that the incidence, magnitude and duration of acute pain experienced by the neurosurgical patients were quantified. ${ }^{[4]}$ Subsequently, many studies have highlighted the unsatisfactory pain management following craniotomy. ${ }^{[5,6]}$ As an aftermath of various studies, accumulated body of evidence has shown that approximately $60 \%$ of post-craniotomy patients experience moderate-to-severe pain up to the $2^{\text {nd }}$ post-operative day or present with persistent pain with neuropathic elements several months after surgery. ${ }^{[3,4,7-10]}$ Although the incident and intensity of post-operative headache tend to decrease with passage of time, there may be serious impact on patients' everyday life. ${ }^{[11]}$

In 1996, Quiney et al. reported that in the United Kingdom, $84 \%$ of patients, who underwent an elective craniotomy and were treated with codeine, complained of moderate-to-severe post-operative pain at some time during the first $24 \mathrm{~h}$ after surgery. ${ }^{[5]}$ In spite of this observation on ineffectiveness of codeine to offer pain-free post-operative course, $70 \%$ of these neurosurgical centres in 2009 were still relying on codeine or hydrocodeine as first line of analgesics, and only $30 \%$ of centres had switched over their practice to administering morphine to them. ${ }^{[12]}$ Similarly, a survey of Canadian neurosurgeons' choice of analgesic administration following craniotomy was no different in that codeine was the most common first-line analgesic provided to these patients. This practice was associated with substantial increased reliance on potent opioid, that is, morphine for rescue analgesia. ${ }^{[13]}$ Therefore, use of morphine as rescue analgesic is significantly higher amongst patients treated with codeine as the first line of analgesic. Even intramuscular morphine is more effective than codeine in terms of pain relief without any side effects. ${ }^{[14]}$ In theory, the side effects profile of codeine should not differ from morphine, which is codeine's active metabolite. ${ }^{[15]}$

In India, there is no published information on the modalities of pain management in patients following craniotomy. However, a survey conducted a couple of years ago in this regard highlighted the reluctance on the part of healthcare providers to administer opioids out of ignorance and also from fear of their side effects. Despite $72 \%$ of respondents acknowledging that these patients experienced unacceptable level of pain, only a miniscule number of neurosurgeons (3\%) administered morphine, while $32 \%$ relied on fentanyl, $13 \%$ infiltrated the wound with local anaesthetics, but majority $(42 \%)$ of them believed that non-steroidal anti-inflammatory drugs alone were sufficient to deliver on this front (unpublished data, 2008). Although useful analgesic in these patients, owing to its shorter duration of action, fentanyl as intravenous patient-controlled analgesia (PCA) is more effective than its administration on as and when required basis. ${ }^{[16,17]}$ Even PCA morphine provides superior analgesia, to alleviate psychological stress with good patient satisfaction and without causing excessive sedation, vomiting or ventilation depression when compared to codeine in adult neurosurgical patients. ${ }^{[18,19]}$ Therefore, titrated properly, opioids do not increase the side effects as compared with codeine. ${ }^{[20]}$ 
Non-narcotics, ketoprofen and paracetamol may be useful as supplemental, opioid-sparing drugs. ${ }^{[20]}$ However, these drugs given as sole analgesics, especially during first $24 \mathrm{~h}$ to $48 \mathrm{~h}$, are ineffective to provide optimal analgesia. Similarly, attempts to circumvent side effects of opioids by pre-incision scalp infiltration with local anaesthetic have shown inconsistent results. ${ }^{[21,22]}$ Thus, all these modalities of pain relief in these patients are poor substitutes of strong opioids. Similar to adult patients, in children too, multimodal analgesia has been recommended maximising pain control with smaller dose of opioids. ${ }^{[23]}$

With the available literature, the healthcare workers are now realising that the traditional justification for avoiding morphine or other strong opioids in the treatment of post-craniotomy pain is largely based on weak evidence. Although it is emerging that opioids are safe and provide effective analgesia following craniotomy, many regimens have been investigated aiming to reduce their dose in acute pain of craniotomy. A recently published systematic review on this subject concluded that as of now, no definite recommendation can be made due to a significant divergence in the methodology of available studies. Limited evidence of scalp infiltration/block suggests an adequate analgesic effect for the first few hours of post-operative period only. Although opioids provide superior analgesia to other analgesics with no significant side effects, the quality of studies was low. ${ }^{[24,25]}$

Poorly controlled post-craniotomy pain may be a harbinger of chronic headache in some patients. Chronic pain of craniotomy has the characteristics of a combination of tension type and site of injury headache over the craniotomy area. It has characteristics of sharp aching, pressure type or throbbing pain. Exact incidence of chronic headache following craniotomy is not known, being different in various studies. ${ }^{[6-29]}$ Many factors determine its incidence, for example, type of craniotomy, anatomical site of craniotomy, craniectomy versus craniotomy, use of fibrin glue, extent of bone drilling, pre-existing degenerative cervical spine disease and scar tissue binding the nerve/s. Chronic headache negatively impacts patients' psychosocial behaviour. Therefore, significance of aggressive control of acute post-craniotomy pain should be given serious consideration. Harner et al. ${ }^{[28]}$ have described following four grades of headache at 3-month post-procedure:

- Grade 1: a relatively minor annoyance

- Grade 2: headache persistent almost everyday

- Grade 3: the patient requires medication everyday

- Grade 4: the patient feels incapacitated.

Many pharmacological and non-pharmacological combination therapies have been practiced to treat this painful entity.
Thus, we have a painful problem at hand to find an effective analgesic regimen for these patients. However, still, there is a need for larger trials to delineate safety and efficacy of opioids for treating acute pain and also to shield them from agony of chronic pain development in future. Therefore, let us not disregard the heart rending cries of post-craniotomy patients merely a cry in wilderness, it merits an urgent attention to stop their pain it in its track.

\section{Parmod K. Bithal}

\author{
Department of Anesthesiology and OR Administration, \\ Division of Neuroanesthesia, King Fahad Medical City, \\ Riyadh, Kingdom of Saudi Arabia \\ Address for correspondence: \\ Dr. Parmod K. Bithal, \\ Department of Anesthesiology and OR Administration, \\ Division of Neuroanesthesia, King Fahad Medical City, Riyadh, \\ Kingdom of Saudi Arabia. \\ E-mail: bithal.parmod@gmail.com
}

\section{REFERENCES}

1. Dunbar PJ, Visco E, Lam AM. Craniotomy procedures are associated with less analgesic requirements than other surgical procedures. Anesth Analg 1999;88:335-40.

2. Guilkey RE, Von Ah D, Carpenter JS, Stone C, Draucker CB. Integrative review: Postcraniotomy pain in the brain tumour patient. J Adv Nurs 2016;72:1221-35.

3. Flexman AM, Ng JL, Gelb AW. Acute and chronic pain following craniotomy. Curr Opin Anaesthesiol 2010;23:551-7.

4. De Benedittis G, Lorenzetti A, Migliore M, Spagnoli D, Tiberio F, Villani RM. Postoperative pain in neurosurgery: A pilot study in brain surgery. Neurosurgery 1996;38:466-9.

5. Quiney N, Cooper R, Stoneham M, Walters F. Pain after craniotomy. A time for reappraisal? $\mathrm{Br} \mathrm{J}$ Neurosurg 1996;10:295-9.

6. Verchère E, Grenier B, Mesli A, Siao D, Sesay M, Maurette P. Postoperative pain management after supratentorial craniotomy. J Neurosurg Anesthesiol 2002;14:96-101.

7. Leslie K, Troedel S, Irwin K, Pearce F, Ugoni A, Gillies R, et al. Quality of recovery from anesthesia in neurosurgical patients. Anesthesiology 2003;99:1158-65.

8. Mordhorst C, Latz B, Kerz T, Wisser G, Schmidt A, Schneider A, et al. Prospective assessment of postoperative pain after craniotomy. J Neurosurg Anesthesiol 2010;22:202-6.

9. Headache Classification Committee of the International Headache Society (IHS). The international classification of headache disorders, $3^{\text {rd }}$ edition (beta version). Cephalalgia 2013;33:629-808.

10. Gottschalk A, Berkow LC, Stevens RD, Mirski M, Thompson RE, White ED, et al. Prospective evaluation of pain and analgesic use following major elective intracranial surgery. J Neurosurg 2007; 106:210-6.

11. Rocha-Filho PA. Post-craniotomy headache: A clinical view with a focus on the persistent form. Headache 2015;55:733-8.

12. Kotak D, Cheserem B, Solth A. A survey of post-craniotomy analgesia in British neurosurgical centres: Time for perceptions and prescribing to change? Br J Neurosurg 2009;23:538-42.

13. Hassouneh B, Centofanti JE, Reddy K. Pain management in post-craniotomy patients: A survey of Canadian neurosurgeons. Can J Neurol Sci 2011;38:456-60.

14. Goldsack C, Scuplak SM, Smith M. A double-blind comparison 
of codeine and morphine for postoperative analgesia following intracranial surgery. Anaesthesia 1996;51:1029-32.

15. Williams DG, Patel A, Howard RF. Pharmacogenetics of codeine metabolism in an urban population of children and its implications after intracranial tumoral reception for analgesic reliability. Br J Anaesth 2002;89:839-45.

16. Morad AH, Winters BD, Yaster M, Stevens RD, White ED, Thompson RE, et al. Efficacy of intravenous patient-controlled analgesia after supratentorial intracranial surgery: A prospective randomized controlled trial. Clinical article. J Neurosurg 2009;111:343-50.

17. Morad A, Winters B, Stevens R, White E, Weingart J, Yaster M, et al. The efficacy of intravenous patient-controlled analgesia after intracranial surgery of the posterior fossa: A prospective, randomized controlled trial. Anesth Analg 2012;114:416-23.

18. Sudheer PS, Logan SW, Terblanche C, Ateleanu B, Hall JE. Comparison of the analgesic efficacy and respiratory effects of morphine, tramadol and codeine after craniotomy. Anaesthesia 2007;62:555-60.

19. Jellish WS, Leonetti JP, Sawicki K, Anderson D, Origitano TC. Morphine/ondansetron PCA for postoperative pain, nausea, and vomiting after skull base surgery. Otolaryngol Head Neck Surg 2006;135:175-81.

20. Nemergut EC, Durieux ME, Missaghi NB, Himmelseher S. Pain management after craniotomy. Best Pract Res Clin Anaesthesiol 2007;21:557-73.

21. Biswas BK, Bithal PK. Preincision $0.25 \%$ bupivacaine scalp infiltration and postcraniotomy pain: A randomized double-blind, placebo-controlled study. J Neurosurg Anesthesiol 2003;15:234-9.

22. Zhou H, Ou M, Yang Y, Ruan Q, Pan Y, Li Y. Effect of skin infiltration with ropivacaine on postoperative pain in patients undergoing craniotomy. Springerplus 2016;5:1180.

23. Shay JE, Kattail D, Morad A, Yaster M. The postoperative management of pain from intracranial surgery in pediatric neurosurgical patients. Paediatr Anaesth 2014;24:724-33.
24. Hansen MS, Brennum J, Moltke FB, Dahl JB. Pain treatment after craniotomy: Where is the (procedure-specific) evidence? A qualitative systematic review. Eur J Anaesthesiol 2011;28:821-9.

25. Tsaousi GG, Logan SW, Bilotta F. Postoperative pain control following craniotomy: A systematic review of recent clinical literature. Pain Pract 2016. doi:10.1111/papr.12548.

26. Gee JR, Ishaq Y, Vijayan N. Postcraniotomy headache. Headache 2003;43:276-8.

27. Kaur A, Selwa L, Fromes G, Ross DA. Persistent headache after supratentorial craniotomy. Neurosurgery 2000;47:633-6.

28. Harner SG, Beatty CW, Ebersold MJ. Headache after acoustic neuroma excision. Am J Otol 1993;14:552-5.

29. Schaller B, Baumann A. Headache after removal of vestibular schwannoma via the retrosigmoid approach: A long-term follow-up-study. Otolaryngol Head Neck Surg 2003;128:387-95.

This is an open access article distributed under the terms of the Creative Commons Attribution-NonCommercial-ShareAlike 3.0 License, which allows others to remix, tweak, and build upon the work non-commercially, as long as the author is credited and the new creations are licensed under the identical terms.

\begin{tabular}{|l|l|}
\hline \multicolumn{2}{|c|}{ Access this article online } \\
\hline Quick Response Code: & Website: \\
\hline & www.jnaccjournal.org \\
\hline & \\
\hline
\end{tabular}

How to cite this article: Bithal PK. Post-craniotomy pain: A neglected entity. J Neuroanaesthesiol Crit Care 2017;4:135-7. 